\title{
EVALUASI TERHADAP PENGGUNAAN LAHAN DAN POLA RUANG DALAM RENCANA TATA RUANG WILAYAH DI KABUPATEN PONTIANAK, PROVINSI KALIMANTAN BARAT
}

\section{Evaluation of Actual Landuse and Official Spatial Land Use Planning in Pontianak Regency, West Kalimantan Province}

\author{
Miranti Anisa Tejaningrum 1)*, Muhammad Ardiansyah2) dan Widiatmaka ${ }^{2)}$ \\ 1) Alumni Program Studi Ilmu Perencanaan Wilayah, Sekolah Pascasarjana IPB, J1. Meranti Kampus IPB Dramaga, \\ Bogor 16680 \\ 2) Departemen Ilmu Tanah dan Sumberdaya Lahan, Fakultas Pertanian IPB, J1. Meranti Kampus IPB Dramaga, \\ Bogor 16680
}

\begin{abstract}
Land needs to be planned for its use through the selection of land use which is in accordance with land capability, so that land use can provide high production and sustainable. The objective of this study was to evaluate actual land use and land use planning, based on land capability. The methodology is confrontation between land capability, actual land use, and spatial patterns in the Spatial Plan. The research was conducted in Pontianak Regency. The result of the research shows that Pontianak Regency has the land capability class of II, III, IV, V and VI. Land class V, was dominant, covering $31 \%$ of the st udy area, with drainage as limiting factor. Land class II covering $24 \%$ of the total area, with soil texture, drainage and slope as limiting factor. At present, $79 \%$ of the area of Pontianak Regency has land use which is in accordance with the land capability, while $21 \%$ of the area, its land use exceeds its land capability. As much as $81 \%$ of the area of Pontianak Regency has been allocated in the Spatial Plan in accordance with land capability, while 19\% of the area, the allocation of the spatial pattern exceeds land capability.
\end{abstract}

Keywords: Actual land use, land capability, spatial planning

\begin{abstract}
ABSTRAK
Lahan perlu direncanakan penggunaannya melalui pemilihan penggunaan lahan (land use) yang sesuai dengan kemampuan lahannya, agar penggunaan lahan dapat memberikan hasil produksi yang tinggi, namun sekaligus juga tetap menjaga agar sumberdaya lahan dapat digunakan secara berkelanjutan. Tujuan penelitian ini adalah untuk mengevaluasi penggunaan lahan aktual dan rencana penggunaan lahan. Evaluasi dilakukan dengan berbasis pada kemampuan lahan. Metodologi yang digunakan adalah konfrontasi antara kemampuan lahan, penggunaan lahan aktual dan alokasi pola ruang dalam Rencana Tata Ruang Wilayah. Penelitian dilakukan di Kabupaten Pontianak. Hasil penelitian menunjukkan bahwa Kabupaten Pontianak memiliki kelas kemampuan lahan II, III, IV, V dan VI. Lahan dengan kelas kemampuan lahan V dominan, mencakup luas $31 \%$ dari luas wilayah penelitian, dengan faktor penghambat drainase. Lahan dengan kemampuan lahan kelas II mencakup 24\% dari luas wilayah, dengan faktor penghambat tekstur, drainase dan lereng. Saat ini, 79\% luas wilayah Kabupaten Pontianak, penggunaan lahannya telah sesuai dengan kemampuan lahannya, sementara $21 \%$ dari luas wilayah, penggunaan lahannya melebihi kemampuan lahannya. Sebesar 81\% luas wilayah Kabupaten Pontianak telah dialokasikan dalam RTRW sesuai dengan kemampuan lahannya, sedangkan $19 \%$ luas wilayah, alokasi pola ruangnya melebihi kemampuan kemampuan lahan.
\end{abstract}

Kata kunci: Kemampuan lahan, penggunaan lahan aktual, pola ruang

\section{PENDAHULUAN}

Kabupaten Pontianak merupakan salah satu wilayah di Provinsi Kalimantan Barat dimana pertanian merupakan salah satu sektor penting bagi perekonomian daerah. Di wilayah ini, sektor pertanian memiliki Produk Domestik Regional Bruto (PDRB) paling tinggi dibandingkan sektor lain, yaitu sebesar $26.63 \%$ dari total PDRB kabupaten (BPS Kabupaten Pontianak, 2015). Tingginya PDRB sektor pertanian ini mencerminkan tingginya aktivitas atau luasnya wilayah pertanian. Memang, salah satu tujuan yang ingin dicapai dalam pembangunan wilayah di Kabupaten Pontianak adalah meningkatkan pendapatan dari sektor pertanian. Salah satu caranya adalah melalui intensifikasi dan ektensifikasi pertanian. Pada masa mendatang, agar tujuan tersebut tercapai secara berkelanjutan, kelestarian lingkungan perlu diperhatikan melalui pengusahaan pertanian hanya pada lahan dengan kemampuan dan daya dukung yang cukup.

Lahan berfungsi sebagai ruang dan tapak dari kegiatan pembangunan dan merupakan faktor produksi utama dari kegiatan pertanian. Luas lahan yang terbatas dibandingkan dengan kebutuhan yang semakin meningkat seiring dengan meningkatnya jumlah penduduk mengharuskan perencanaan dilakukan dengan seksama. Pertumbuhan penduduk yang cepat membutuhkan daerah baru untuk pemenuhan kebutuhan primer (Widiatmaka et al., 2015), yang akan berpengaruh terhadap perubahan 
penggunaan lahan. Ketersediaan lahan yang terbatas dan luas yang relatif tetap menyebabkan terjadinya persaingan antar jenis penggunaan lahan. Dalam persaingan tersebut, keputusan penggunaan lahan biasanya didasarkan pada penggunaan yang memberikan nilai ekonomi yang paling tinggi. Dalam konteks demikian, aspek daya dukung lahan perlu menjadi pertimbangan. Penataan ruang dan lahan perlu didasarkan pada pertimbangan rasional sesuai dengan potensi wilayah tersebut, agar terjadi efisiensi penggunaan ruang tanpa menurunkan kualitas lahan. Penurunan kualitas lahan dapat berdampak pada rusaknya lingkungan dan resiko bencana yang dapat muncul secara tidak terduga (Junaedi, 2008). Karena itu, penggunaan lahan perlu direncanakan dengan memilih pengunaan lahan yang seusai dengan kemampuannya, agar hasil yang tinggi dapat diperoleh dengan sekaligus tetap menjaga agar sumberdaya tidak terdegradasi (Widiatmaka et al., 2012)

Tinjauan lebih detil pada sektor pertanian di Provinsi Kalimantan Barat menunjukkan bahwa sub-sektor perkebunan berperan besar dalam mendukung perekonomian wilayah. Kontribusi sub-sektor ini mencapai $10.71 \%$ (BPS Provinsi Kalimantan Barat, 2015). Peningkatan perluasan areal perkebunan ini menyumbang peningkatan PDRB wilayah provinsi tersebut. Meluas cepatnya perkebunan berpotensi menyebabkan perubahan besar penggunaan lahan hutan menjadi penggunaan lahan perkebunan.

Meningkat cepatnya jumlah penduduk di Kabupaten Pontianak, dari 227,998 orang pada tahun 2008 menjadi 245,924 orang pada tahun 2014 (BPS Kabupaten Pontianak 2010; 2015) juga merupakan salah satu faktor pendorong yang menyebabkan terjadinya kompetisi penggunaan lahan dan ruang, yang selanjutnya berimplikasi pada tingginya perubahan penggunaan lahan. Agar sumberdaya lahan dapat dimanfaatkan secara optimal dengan tanpa merusak, maka pemanfaatan lahan perlu direncanakan, dengan berbasis pada daya dukung lingkungan. Salah satu cara untuk melakukan evaluasi daya dukung lingkungan adalah evaluasi berbasis kemampuan lahan (Widiatmaka et al., 2015).

Pelestarian fungsi lingkungan hidup dapat terjamin dengan kegiatan pemanfaatan lahan dan ruang yang memperhatikan daya dukung lingkungan. Daya dukung lingkungan perlu menjadi pertimbangan penting dalam penataan ruang, baik dalam penyusunan Rencana Tata Ruang Wilayah (RTRW) maupun evaluasi pemanfaatan ruang (Wirosoedarmo et al., 2014). Menurut UU 32/2009 tentang Perlindungan dan Pengelolaan Lingkungan Hidup, daya dukung lingkungan hidup adalah kemampuan lingkungan hidup untuk mendukung perikehidupan manusia, makhluk hidup lain dan keseimbangan antar keduanya. Sementara itu, pelestarian daya dukung lingkungan hidup adalah rangkaian upaya untuk melindungi kemampuan lingkungan hidup terhadap tekanan perubahan dan atau dampak negatif yang ditimbulkan oleh suatu kegiatan, agar tetap mampu mendukung perikehidupan manusia dan makhluk hidup lain.

Penilaian daya dukung lingkungan pada suatu lahan dapat dilakukan dengan berbasis kemampuan lahannya. Lahan yang mempunyai kelas kemampuan tinggi memiliki pilihan penggunaan lahan yang lebih banyak, baik untuk pertanian, kehutanan maupun tujuan lain seperti permukiman, industri sarana infrastruktur dan lainnya.
Lahan dengan kelas kemampuan rendah memiliki keterbatasan dalam pemanfaatannya karena banyaknya kendala dan faktor pembatas yang harus diatasi sebelum lahan dapat dimanfaatkan. Lahan yang digunakan dengan tanpa mempertimbangkan kemampuan lahannya akan mengakibatkan rusaknya lahan tersebut, bahkan dapat menyebabkan terjadinya bencana. Lahan dengan kelas kemampuan lahan rendah hanya dapat digunakan untuk penggunaan lahan yang tidak intensif atau sama sekali dilarang untuk dimanfaatkan untuk diambil hasil produknya secara langsung. Peruntukan yang disarankan bagi lahan kelas kemampuan lahan yang paling rendah adalah kawasan lindung (Fithriah, 2011).

Tujuan penelitian ini adalah untuk melakukan evaluasi daya dukung lingkungan berbasis kemampuan lahan di Kabupaten Pontianak. Evaluasi dilakukan terhadap penggunaan lahan aktual dan alokasi Pola Ruang dalam Rencana Tata Ruang Wilayah Kabupaten Pontianak.

\section{BAHAN DAN METODE}

Penelitian ini dilaksanakan pada bulan Januari sampai dengan Oktober 2015. Penelitian dilakukan di Kabupaten Pontianak, yang secara geografis terletak pada $1^{\circ} 10^{\prime}$ LU dan $0^{\circ} 35^{\prime \prime}$ LS serta diantara $109^{\circ} 45^{\prime \prime}-111^{\circ} 11^{\prime \prime}$ BT. Lokasi penelitian disajikan pada Gambar 1.

Bahan-bahan yang digunakan dalam penelitian ini antara lain adalah data-data spasial, mencakup peta penggunaan lahan tahun 2014, peta alokasi pola ruang dalam RTRW Kabupaten Pontianak (2014-2034) dan peta sistem lahan (land system). Peralatan yang digunakan dalam penelitian ini berupa seperangkat komputer yang dilengkapi dengan perangkat lunak yang menunjang kegiatan analisis spasial, antara lain Arc GIS 10.2 dan MS Excel.

\section{Analisis Data}

Tahap pertama yang dilakukan dalam penelitian ini adalah analisis dan klasifikasi kemampuan lahan. Data-data untuk penentuan kelas dan sub kelas kemampuan lahan diperoleh dari beberapa peta, antara lain peta kelas lereng, peta tanah, dan peta drainase. Dari peta-peta tersebut dibuat satuan lahan pengamatan. Verifikasi lapang, sampling dan analisis dilakukan pada 30 titik yang tersebar di seluruh wilayah Kabupaten Pontianak. Satuan lahan dan hasil verifikasinya menjadi dasar identifikasi kelas kemampuan lahan. Kriteria klasifikasi kemampuan lahan yang digunakan disajikan pada Tabel 1, bersumber dari Arsyad (2006) dan Hardjowigeno dan Widiatmaka (2007). Meskipun demikian, beberapa parameter kemampuan lahan seperti kepekaan erosi dan batuan permukaan tidak digunakan dalam penelitian ini karena keterbatasan data.

Setelah analisis kemampuan lahan dilakukan, Peta Kemampuan Lahan yang dihasilkan selanjutnya digunakan untuk mengevaluasi penggunaan lahan aktual, dalam hal ini penggunaan lahan tahun 2014 dan alokasi lahan pada pola ruang dalam RTRW Kab. Pontianak 2014-2025. Konsep analisis yang berupa konfrontasi kemampuan lahan dengan penggunaan lahan dan alokasi penggunaan lahan ini didasarkan pada Peraturan Menteri Negara Lingkungan Hidup No. 17 tahun 2009 tentang Evaluasi Daya Dukung untuk Penataan Ruang Wilayah. 
Tabel 1. Kriteria klasifikasi kemampuan lahan

\begin{tabular}{|c|c|c|c|c|c|c|c|c|c|}
\hline \multirow{2}{*}{ No } & \multirow{2}{*}{ Faktor penghambat } & \multicolumn{8}{|c|}{ Kelas kemampuan lahan } \\
\hline & & $\mathrm{I}$ & II & III & IV & $\mathrm{V}$ & VI & VII & VIII \\
\hline 1 & Tekstur tanah Lapisan atas $(40 \mathrm{~cm})$ & h-s & h-s & h-ak & h-ak & $(*)$ & h-ak & h-ak & $\mathrm{K}$ \\
\hline 2 & Lereng permukaan $(\%)$ & $0-3$ & $3-8$ & $8-15$ & $15-30$ & $0-3$ & $30-45$ & $45-65$ & $>65$ \\
\hline 3 & Drainase & d1 & $\mathrm{d} 2$ & $\mathrm{~d} 3$ & $\mathrm{~d} 4$ & d5 & $(* *)$ & $(* *)$ & d0 \\
\hline 4 & Kedalaman efektif & $>90$ & $90-50$ & $50-25$ & $<25$ & $(*)$ & $(*)$ & $(*)$ & $(*)$ \\
\hline 5 & Keadaan erosi & $\mathrm{e} 0$ & e1 & $\mathrm{e} 2$ & $\mathrm{e} 3$ & $(* *)$ & $\mathrm{e} 4$ & $\mathrm{e} 5$ & $(*)$ \\
\hline 6 & Kepekaan erosi & $\mathrm{KE} 1 / 2$ & KE3 & KE4/5 & KE6 & $(*)$ & $(*)$ & $(*)$ & $(*)$ \\
\hline 7 & Kerikil/batuan (\%volume) & $0-15$ & $0-15$ & $15-50$ & $50-90$ & $>90$ & $(*)$ & $(*)$ & $>90$ \\
\hline 8 & Banjir & $\mathrm{O} 0$ & $\mathrm{O} 1$ & $\mathrm{O} 2$ & $\mathrm{O} 3$ & $\mathrm{O} 4$ & $(* *)$ & $(* *)$ & $(*)$ \\
\hline
\end{tabular}

Keterangan:

(*) : dapat mempunyai sembarang sifat penghambat

(**) : tidak berlaku

Tekstur $\quad$ : ah: agak halus; h: halus; ak: agak kasar; k: kasar; s: sedang

Erosi $\quad$ : e0: tidak ada; e1: ringan; e2: sedang; e3: agak berat; e4: berat; e5: sangat berat

Drainase $\quad$ d0: berlebih; d1: baik; d2: agak baik; d3: agak buruk; d4: buruk; d5: sangat buruk

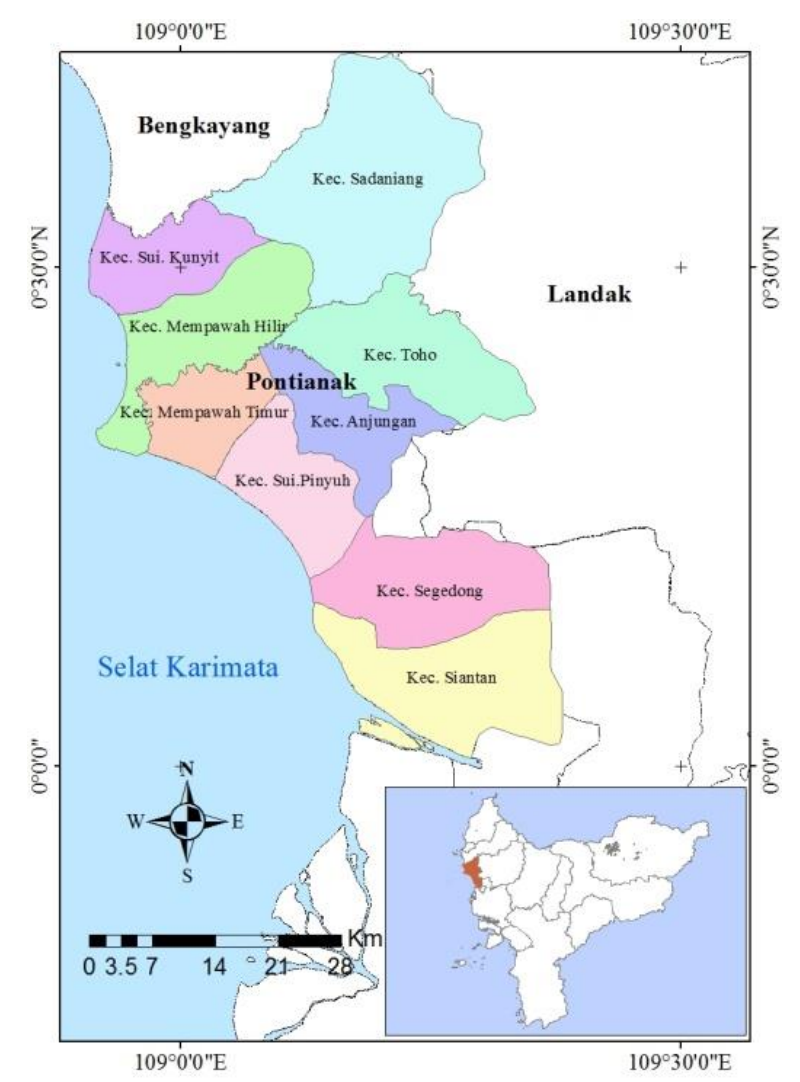

Gambar 1. Peta administrasi Kabupaten Pontianak

\section{HASIL DAN PEMBAHASAN}

\section{Kemampuan Lahan}

Hasil analisis kemampuan lahan menunjukkan bahwa Kabupaten Pontianak memiliki lahan dengan kelas kemampuan lahan yang berkisar dari kelas II, III, IV, V dan VI. Berdasarkan luas wilayahnya, lahan pada kelas kemampuan lahan $\mathrm{V}$ memiliki luas terbesar yaitu sebesar $31 \%$ dari luas wilayah. Faktor penghambat utama pada lahan kelas ini adalah drainase. Lahan pada kelas kemampuan lahan II juga relatif luas, yaitu sebesar 24\% dari luas wilayah. Faktor penghambat pada lahan kelas II di wilayah ini adalah tekstur, drainase dan kemiringan lereng. Peta kemampuan lahan disajikan pada Gambar 2. Luasan untuk masing-masing kelas kemampuan lahan disajikan pada Tabel 2 .

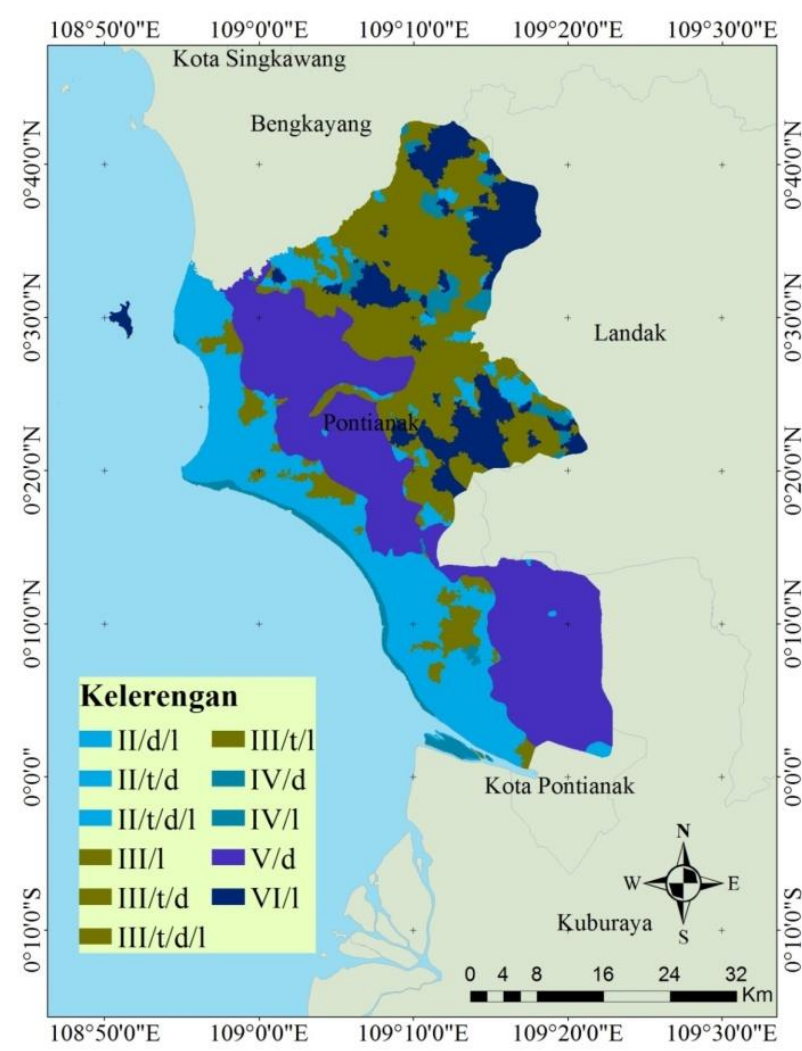

Gambar 2. Peta kelas kemampuan lahan Kabupaten Pontianak

Tabel 2. Luasan kelas kemampuan lahan Kabupaten Pontianak

\begin{tabular}{lrr}
\hline \multirow{2}{*}{ Kelas Kemampuan Lahan } & \multicolumn{2}{c}{ Jumlah } \\
\cline { 2 - 3 } & Area (ha) & Persen (\%) \\
\hline II//d/l & 6,206 & 3.01 \\
II/t/d & 3,235 & 1.57 \\
II/t/d/l & 41,981 & 20.36 \\
III/l & 4,731 & 2.29 \\
III/t/d & 4,473 & 2.17 \\
III/t/d/l & 13,467 & 6.53 \\
III/t/l & 35,342 & 17.14 \\
IV/d & 3,631 & 1.76 \\
IV/l & 5,020 & 2.43 \\
V/d & 65,081 & 31.56 \\
VI/l & 23,041 & 11.17 \\
\hline
\end{tabular}




\section{Kesesuaian Kemampuan Lahan terhadap Penggunaan Lahan Aktual dan Pola ruang}

Menurut Hardjowigeno dan Widiatmaka (2007), lahan dengan kelas kemampuan lahan I sampai dengan IV merupakan lahan yang sesuai untuk usaha pertanian. Lahan dengan kelas kemampuan V sampai VIII tidak sesuai untuk usaha pertanian atau diperlukan biaya yang tinggi untuk pengelolaannya untuk pertanian. Lahan dengan kelas kemampuan lahan V di Kabupaten Pontianak memiliki faktor pembatas drainase. Lahan demikian tidak cocok untuk tanaman pertanian, sehingga dalam hal ini peruntukan penggunaannya adalah sebagai tanaman rumput, padang penggembalaan, hutan produksi atau hutan lindung dan cagar alam.

Jika dikonfrontasikan dengan penggunaan lahan aktual tahun 2014, luasan terbesar penggunaan lahan pada kelas kemampuan $\mathrm{V}$ adalah penggunaan hutan rawa, perkebunan dan lahan kosong.

Hasil lengkap konfrontasi antara kemampuan lahan dengan penggunaan lahan tahun aktual tahun 2014 dan dengan pola ruang disajikan pada Tabel 3. Tabel tersebut menginformasikan bahwa baik penggunaan lahan aktual maupun alokasi peruntukan pada pola ruang pada lahanlahan dengan kelas kemampuan lahan tinggi (II, III dan IV), pada umumnya masih selaras. Artinya, penggunaan lahan maupun alokasi perencanaannya masih sejalan dengan daya dukung berbasis kemampuan lahannya. Sementara itu, pada lahan dengan kelas kemampuan lahan V dan VI masih terdapat penggunaan lahan aktual dan peruntukan lahan pada pola ruang yang tidak selaras dengan kemampuan lahannya, walaupun relatif kecil dan tidak terlalu luas. Meskipun penyimpangan ini relatif kecil, namun sebaiknya pada masa depan, baik penggunaan lahan maupun alokasi peruntukan lahan pada pola ruang dapat diarahkan agar lebih selaras dengan kemampuan lahannya.

Analisis keselarasan antara kemampuan lahan terhadap penggunaan lahan aktual dan alokasi pada pola ruang secara umum menunjukkan bahwa masih terdapat sebagian kecil penggunaan dan peruntukan lahan pada pola ruang yang tidak selaras dengan kemampuan lahannya (Tabel 4).

Tabel 3. Keselarasan antara kemampuan lahan terhadap penggunaan lahan aktual tahun 2014 dan pola ruang

\begin{tabular}{|c|c|c|c|c|c|c|c|c|c|}
\hline \multirow{2}{*}{$\mathrm{KL}$} & \multirow{2}{*}{$\begin{array}{l}\text { Luas } \\
\text { (ha) }\end{array}$} & \multirow{2}{*}{ PLA } & \multirow{2}{*}{ KL-PL } & \multicolumn{2}{|c|}{ Luas } & \multirow{2}{*}{ PR } & \multirow{2}{*}{ KL-PR } & \multicolumn{2}{|c|}{ Luas } \\
\hline & & & & $\mathrm{Ha}$ & $\%$ & & & ha & $\%$ \\
\hline II & 51,453 & $\begin{array}{l}\text { B, BR, HLK, HM, HR, LK, Kbn, } \\
\text { Pmk, PLK, PLKC, Swh, Tbk, } \\
\text { Tbg, TA }\end{array}$ & $\mathrm{S}$ & 51,453 & 100.00 & $\begin{array}{l}\text { KBL, KHP, KL, KK, } \\
\text { KP, KT, Tbk, TA }\end{array}$ & $\mathrm{S}$ & 51,453 & 100.00 \\
\hline III & 58,041 & $\begin{array}{l}\text { B, BR, HLK, HM, HR, LK, Kbn, } \\
\text { Pmk, PLK, PLKC, Swh, Tbg, TA }\end{array}$ & $\mathrm{S}$ & 58,041 & 100.00 & $\begin{array}{l}\text { KBL, KHP, KL, KK, } \\
\text { KP, KT, TA }\end{array}$ & $S$ & 58,041 & 100.00 \\
\hline IV & 8,658 & $\begin{array}{l}\text { B, BR, HLK, HM, HR, LK, Kbn, } \\
\text { Pmk, PLK, PLKC, Swh, Tbk, } \\
\text { Tbg, TA }\end{array}$ & $\mathrm{S}$ & 8,658 & 100.00 & $\begin{array}{l}\text { KBL, KHP, KL, KK, } \\
\text { KP, KT, TA }\end{array}$ & $\mathrm{S}$ & 8,658 & 100.00 \\
\hline \multirow[t]{2}{*}{ V } & 65,099 & $\mathrm{~B}, \mathrm{BR}, \mathrm{HR}, \mathrm{TA}$ & $\mathrm{S}$ & 34,166 & 52.48 & KHP, KL, TA & $S$ & 44,614 & 68.53 \\
\hline & & LK, Kbn, Pmk, PLK, PLKC, Swh & TS & 30,933 & 47.52 & KBL, KK, KP, KT & TS & 20,485 & 31.47 \\
\hline \multirow[t]{2}{*}{ VI } & 23,057 & B, HM, HLK, HR, Tbg & $\mathrm{S}$ & 10,742 & 46.63 & KHP, KL & $S$ & 4,464 & 19.36 \\
\hline & & LK, Kbn, Pmk, PLKC, Swh & TS & 12,315 & 53.37 & KBL, KP, KT & $\mathrm{TS}$ & 18,593 & 80.64 \\
\hline
\end{tabular}

Keterangan:

KL: Kemampuan lahan

PLA: penggunaan lahan aktual; (Ta) tubuh air; (Tbk) tambak; (Swh) sawah; (Plkc) pertanian lahan kering campur semak; (Plk) pertanian lahan kering; (Tbg) pertambangan; (Pmk) permukiman; (Kbn) perkebunan; (Lk) lahan kosong; (Hrs) hutan rawa; (Hlks) hutan lahan kering; (Hms) hutan mangrove; (Br) belukar rawa; (B) belukar

PR: pola ruang; KBL: kawasan budidaya lain; KHP: kawasan hutan produksi; KL: kawasan lindung; KK: kawasan perkebunan; KP: kawasan pertanian; KT: kawasan terbangun; Tbk: tambak; TA: tubuh air

S: selaras; TS: tidak selaras

Tabel 4. Rekapitulasi perhitungan keselarasan antara kemampuan lahan terhadap penggunaan lahan aktual tahun 2014 dan pola ruang

\begin{tabular}{|c|c|c|c|c|c|}
\hline \multirow{2}{*}{ No } & \multirow{2}{*}{ KL } & \multicolumn{2}{|c|}{ Luas KL-PLA } & \multicolumn{2}{|c|}{ Luas KL-PR } \\
\hline & & ha & $\%$ & ha & $\%$ \\
\hline \multirow{4}{*}{1} & Lahan berkemampuan ting & & & & \\
\hline & $\mathrm{S}$ & 118,078 & 100.00 & 118,078 & 100.00 \\
\hline & TS & & & & \\
\hline & Jumlah & 118,078 & 100.00 & 118,078 & 100.00 \\
\hline \multirow{4}{*}{2} & Lahan berkemampuan ting & & & & \\
\hline & $\mathrm{S}$ & 39,900 & 45.28 & 49,043 & 55.66 \\
\hline & TS & 48,216 & 54.72 & 39,073 & 44.34 \\
\hline & Jumlah & 88,116 & 100.00 & 88,116 & 100.00 \\
\hline \multirow{4}{*}{3} & Total semua kelas (II-VI) & & & & \\
\hline & $\mathrm{S}$ & 157,978 & 76.62 & 167,121 & 81.06 \\
\hline & TS & 48,216 & 23.38 & 39,073 & 18.94 \\
\hline & Jumlah & 206,194 & 100.00 & 206,194 & 100.00 \\
\hline
\end{tabular}




\section{SIMPULAN}

Kabupaten Pontianak memiliki lahan dengan kelas kemampuan lahan yang berkisar dari kelas II, III, IV, V dan VI. Berdasarkan luas wilayahnya, lahan dengan kelas kemampuan lahan $\mathrm{V}$ merupakan yang terluas, yaitu sebesar $31 \%$ dari luas wilayah. Faktor penghambat utama pada lahan di wilayah ini adalah drainase. Lahan kelas II memiliki luas sebesar $24 \%$ dari luas wilayah dengan faktor penghambat utama tekstur, drainase dan lereng.

Hasil anlisis menunjukkan bahwa baik penggunaan lahan aktual maupun alokasi peruntukan pada pola ruang pada lahan-lahan dengan kelas kemampuan lahan tinggi (II, III dan IV), pada umumnya sejalan dengan daya dukung berbasis kemampuan lahannya. Di Kabupaten Pontianak, masih terdapat sebagian kecil penggunaan lahan dan peruntukan lahan pada pola ruang yang tidak selaras dengan kemampuan lahannya. Pada lahan demikian, baik penggunaan lahan maupun alokasi peruntukan lahan pada pola ruang pada masa mendatang perlu diarahkan agar lebih selaras dengan kemampuan lahannya.

\section{DAFTAR PUSTAKA}

Arsyad, S. 2006. Konservasi tanah dan air. IPB Press, Bogor.

[BPS]. Badan Pusat Statistik Kabupaten Pontianak. 2010. Kabupaten Pontianak dalam Angka 2010. BPS Kabupaten Pontianak, Mempawah.
[BPS] Badan Pusat Statistik Kabupaten Pontianak. 2015. Kabupaten Pontianak dalam Angka 2015. BPS Kabupaten Pontianak, Mempawah.

[BPS] Badan Pusat Statistik Provinsi Kalimantan Barat. 2015. Kalimantan Barat dalam Angka 2015. BPS Kalimantan Barat, Pontianak.

Hardjowigeno, S. dan Widiatmaka. 2007. Evaluasi kesesuaian lahan dan perencanaan tata guna tanah. Gadjah Mada University Pr., Yogyakarta.

Junaedi, A. 2008. Konsistensi dan inkonsistensi pemanfaatan ruang dan implikasinya terhadap pelaksanaan rencana tata ruang wilayah Kabupaten Sumedang [tesis]. IPB. Bogor.

Widiatmaka, W. Ambarwulan, M.Y.J. Purwanto, Y. Setiawan dan H. Effendi. 2015. Daya Dukung Lingkungan Berbasis Kemampuan Lahan di Tuban, Jawa Timur. Jurnal manusia dan lingkungan, 22 (2): 247-259.

Widiatmaka, S.P. Mulya dan M. Hendrisman. 2012. Analisis kesesuaian lahan tingkat satuan pemukiman menggunakan automated land evaluation system (ALES): studi kasus Rantau Pandan SP-1, Provinsi Jambi. Jurnal Pengelolaan Sumberdaya Alam dan Lingkungan, 1 (2): 46-55. 